Rev. Int. Contam. Ambie. 37, 431-442, 2021

https://doi.org/10.20937/RICA.53821

\title{
EFECTO GENOTÓXICO DE DOS TINTAS EMPLEADAS EN EL ARTE DEL TATUAJE
}

Genotoxic effect of two inks used in the art of tattoo

\author{
Norberto ALARCÓN-HERRERA y Saúl FLORES MAYA*
}

Laboratorio de Recursos Naturales de la Unidad de Biotecnología y Prototipos, Facultad de Estudios Profesionales Iztacala, Universidad Nacional Autónoma de México, Av. de los Barrios 1, Los Reyes Ixtacala, Hab. Los Reyes Ixtacala Barrio de los Árboles/Barrio de los Héroes, 54090 Tlalnepantla de Baz, Estado de México, México.

*Autor para correspondencia: saulsel@unam.mx

(Recibido: diciembre de 2019; aceptado: junio de 2020)

Palabras clave: micronúcleos, aberraciones cromosómicas estructurales, ratón cd-1, linfocitos.

\section{RESUMEN}

El presente estudio aporta respuestas sobre el efecto genotóxico de dos tintas usadas en el arte del tatuaje. En la actualidad no hay información sobre los efectos genotóxicos que puedan producir algunos de los compuestos químicos de las tintas sobre la salud humana. El objetivo de este estudio fue conocer los efectos genotóxicos de la tinta negra y blanca, empleadas mayormente en el arte del tatuaje. En esta investigación se aplicaron la prueba de micronúcleos en células de sangre periférica de ratones CD-1 y la prueba de aberraciones cromosómicas estructurales en cultivos de linfocitos humanos. Los resultados obtenidos mostraron diferencias significativas en los valores promedio de las células en división (\% IM), la frecuencia de micronúcleos (\% MCN) en las células de sangre periférica de los ratones y el número promedio de aberraciones cromosómicas estructurales de las células de linfocitos humanos, por lo que fueron sometidos al análisis de la prueba de comparación múltiple de Dunnett $(\mathrm{p}<0.05)$. Se concluyó que los componentes químicos de las tintas blanca y negra tienen efectos citotóxicos en las células de sangre periférica de ratón CD-1 y en las células de linfocitos humanos. En cuanto a los efectos genotóxicos de dichos compuestos, ambas tintas los producen en células de sangre periférica de ratón CD-1 y sólo la tinta blanca tuvo efectos genotóxicos en las células de linfocitos humanos en la concentración de $10 \mathrm{mg} / \mathrm{mL}$.

Key words: micronuclei, structural chromosomal aberrations, cd-1 mice, lymphocytes

\begin{abstract}
The present study provides answers about the genotoxic effect of two inks used in the art of tattooing. Currently, there is no information on the genotoxic effects that some of the chemical compounds in this inks can produce on human health. The objective of this study was to know the genotoxic effects of black and white ink, mostly used in tattoo art. In this investigation, the micronucleus test was applied in peripheral blood cells of CD-1 mice and the structural chromosomal aberration test in human lymphocyte cultures. The results obtained indicated that the average values of both the dividing cells $(\% \mathrm{IM})$, the frequency of micronuclei $(\% \mathrm{MCN})$ in the peripheral blood cells of the mice
\end{abstract}


and the average number of structural chromosomal aberrations in human lymphocyte cells showed significant differences, therefore they were subjected to Dunnett's multiple comparison test analysis $(\mathrm{p}<0.05)$. It was concluded that the chemical components of the white and black inks have cytotoxic effects in peripheral blood cells of the CD-1 mouse and human lymphocyte cells, while the chemical compounds of the two inks produce genotoxic effects in peripheral blood cells of CD-1 mice and only the white ink had genotoxic effects on human lymphocyte cells at a $10 \mathrm{mg} / \mathrm{ml}$ concentration.

\section{INTRODUCCIÓN}

En años recientes, tatuarse se ha vuelto una actividad altamente popular en muchos países para hombres y mujeres. Un estudio realizado en Australia señala que el porcentaje de adultos que se tatuado alguna vez en su vida incrementó del 10.1 al $14.5 \%$ en un periodo aproximado de siete años (Heywood et al. 2012). En el caso específico de México, uno de cada 10 individuos tiene un tatuaje (es decir, 12 millones de personas), la mayoría de los cuales no sobrepasa los 20 años de edad (CONAPRED 2015). Además de las preocupaciones sobre la transmisión de enfermedades bacterianas que se generan en torno a la práctica de tatuajes, también hay la inquietud sobre los posibles efectos adversos que podría ocasionar la composición química de las tintas para tatuaje (Peta et al. 2015). La mayoría de las tintas consiste prácticamente en pigmentos insolubles mezclados con agua, además de contener dispersantes, adyuvantes y conservadores. (Beute et al. 2008), en tanto que las tintas tradicionales contienen algún tipo de metal (Laux et al. 2016). A pesar de que la mayoría de las tintas modernas contienen pigmentos orgánicos, los metales pesados siguen siendo altamente utilizados, ya sea como cromóforos o como aditivos de sombreado (p. ej., el titanio, el bario, el aluminio y el cobre son utilizados como pigmentos en estas tintas); además, se han reportado otros metales en su composición, como antimonio, arsénico, cadmio, cromo, cobalto, plomo. Inclusive algunos óxidos metálicos (óxido de aluminio, óxido de titanio, etc.) se añaden como nanopartículas con la intención de crear diversos efectos sobre las tintas. Sin embargo, su destino y efectos sobre el cuerpo humano siguen siendo inciertos (Forte et al. 2009a, b, Jacobsen et al. 2012).

Hasta la fecha no hay ningún tipo de regulación sobre la composición de las tintas de tatuaje. Incluso la Food and Drug Administration de EUA (FDA 2007) ha omitido la aprobación de algún tipo de tinta para su uso en tatuajes, y en 2003 el Consejo Europeo hizo hincapié en la necesidad de regular este mercado
(Bäumler et al. 2003). El principal problema para establecer una regulación es la falta de estudios in vivo e in vitro para determinar los efectos genotóxicos de las tintas (Wenzel et al. 2013). Dentro de la escasa información disponible, Peta et al. (2015) determinaron que los hidrocarburos aromáticos policíclicos (HAP) contenidos en la composición química de la tinta negra son responsables solamente de un $0.06 \%$ del estrés oxidativo en la citotoxicidad de bacterias y la citotoxicidad en la prueba de p53,y que el mayor daño citogenotóxico se debe a compuestos no identificados.

En este estudio, la prueba de micronúcleos (MCN) fue empleada en un modelo in vivo, ya que permite analizar simultáneamente información de daños genéticos y citotóxicos, y además se obtienen resultados de una forma relativamente rápida de los daños en células expuestas a las tintas (Hayashi et al. 2001). Por otro lado, también se aplicó una prueba in vitro para detectar aberraciones cromosómicas y alteraciones en el índice mitótico (IM) en cultivo de células de linfocitos humanos (Gómez-Arroyo et al. 1995, Calderón-Segura et al. 1999, Albertini et al. 2000).

Para este estudio se estableció la siguiente interrogante: ¿las tintas de color negro y blanco tienen algún efecto genotóxico? De esta forma, los resultados publicados de esta investigación tendrán un impacto sobre la regulación en la fabricación química de las tintas y en la extrapolación de los efectos de estos pigmentos en la salud humana. Este antecedente quedará para futuros trabajos de investigación, que deberán ser atendidos inmediatamente, por ejemplo, en el análisis de los efectos genotóxicos en personas tatuadas en el 25 a $100 \%$ de la superficie corporal.

\section{MATERIALES Y MÉTODOS}

\section{Extracción de pigmentos}

Se obtuvieron frascos de $2 \mathrm{oz}$ de tinta profesional negra y blanca de la marca Dragonhawks en Mercado Libre, México. Se separaron los pigmentos de cada 
una de las tintas con ayuda de un ultrasonicador marca Hielscher UP100H, utilizando como solvente hexano de la manera siguiente: se mezclaron $2 \mathrm{~mL}$ de tinta en $2 \mathrm{~mL}$ de hexano y $1 \mathrm{~mL}$ de agua destilada, llevando a cabo la sonicación durante $1 \mathrm{~h}$. Posteriormente, las muestras se centrifugaron a $2500 \mathrm{rpm}$ a $14{ }^{\circ} \mathrm{C}$ durante $10 \mathrm{~min}$. Terminada la centrifugación se recuperaron tres fases y mediante evaporación se eliminaron los restos de solvente. Para ambos colorantes se prepararon soluciones madre (stock) con base en la cantidad de pigmentos obtenidos. Considerando las tres fases (agua, hexano y disolventes de las tintas), por cada $2 \mathrm{~mL}$ se obtuvieron $100 \mathrm{mg}$ de pigmentos de tinta blanca y $45 \mathrm{mg}$ de tinta negra.

Se usó agua/etanol en proporción 3:1 como disolvente para ambos pigmentos. La concentración de la solución madre del pigmento negro fue de $43 \mathrm{mg} / \mathrm{mL}$ y de $80 \mathrm{mg} / \mathrm{mL}$ para el pigmento blanco.

\section{Ensayo de micronúcleos Material biológico}

Se usaron ratones machos de la cepa CD-1 de ocho semanas de edad con un peso aproximado de 25 a $30 \mathrm{~g}$ (siguiendo los criterios establecidos por Hayashi et al. [2000]). Los ratones fueron proporcionados por el Bioterio de la Facultad de Estudios Superiores Iztacala de la UNAM. Desde la aclimatación hasta el final del experimento los organismos se mantuvieron en condiciones de laboratorio a $21 \pm 2{ }^{\circ} \mathrm{C}$ con un ciclo de luz-oscuridad 12:12 h, con acceso a alimento especial para ratones y agua ad libitum.

\section{Diseño experimental}

Para determinar las dosis a utilizar y la $\mathrm{DL}_{50} \mathrm{se}$ formaron seis lotes con seis ratones cada uno. Los lotes 1, 2, 3 fueron asignados para administrarles el pigmento blanco y los lotes 4,5 , y 6 para tratamiento con la tinta negra. Las dosis aplicadas a cada lote fueron las siguientes: los lotes 1 y 4 fueron expuestos a dosis de $90 \mathrm{mg} / \mathrm{kg}$, los lotes 2 , y 5 a dosis de 240 $\mathrm{mg} / \mathrm{kg}$ y los lotes 3 y 6 a dosis de $500 \mathrm{mg} / \mathrm{kg}$. Una vez obtenida la $\mathrm{DL}_{50}$, que fue de $240 \mathrm{mg} / \mathrm{kg}$ para cada tinta, se procedió a administrar 1/8, 1/4 y $3 / 8$ de dicha dosis para los ensayos de genotoxicidad y toxicidad.

\section{Tratamientos}

Se establecieron nueve lotes (marcando a los animales previamente), cada uno con cinco organismos de sexo masculino. A los ratones de los lotes designados como 1,2 y 3 se les administraron por vía subcutánea y una sola vez dosis de 30, 60 y $90 \mathrm{mg} / \mathrm{kg}$, respectivamente, de pigmento blanco de la marca
Dragonhawk. A los lotes 4, 5 y 6 se les administraron dosis similares de pigmentos de tinta negra. Los tres lotes restantes se distribuyeron de la siguiente manera: al lote 7 , asignado como testigo negativo, sólo se le proporcionaron agua y alimento especial para roedores; al lote 8 , asignado como testigo positivo, se le aplicó una sola vez una dosis de $60 \mathrm{mg} / \mathrm{kg}(0.3 \mathrm{~mL})$ de Ifosfamida por vía intraperitoneal; finalmente, al lote 9, designado como testigo negativo, se le aplicó una dosis de $0.3 \mathrm{~mL}$ de solución agua/etanol 3:1.

Después de la administración se procedió a extraer sangre a los ratones mediante una punción en la zona caudal a las 24, 48, 72, 96 y $120 \mathrm{~h}$. La gota de sangre se colocó sobre una laminilla y se realizó un frotis (se elaboraron tres laminillas por ratón). Inmediatamente se fijaron las muestras con metanol. Las laminillas se sometieron a un tren de tinción de hematoxilina de Mayer y eosina acuosa al $0.2 \%$ por 10 y 2 min, respectivamente (Megías et al. 2018).

Se contabilizaron las células policromáticas y normocromáticas de la sangre periférica de los ratones con ayuda de un microscopio óptico Leica $(100 \times)$ y posteriormente se fotografiaron utilizando una cámara digital Moticam acoplada a un ordenador. Se contabilizaron un total de 2000 células entre policromáticas $(\mathrm{CP})$ y normocromáticas $(\mathrm{CN})$, así como la frecuencia de eritrocitos policromáticos micronucleados (MCNCP) por ratón y por día.

\section{Análisis estadístico}

Los índices de genotoxicidad (\%) y toxicidad (\%) se calcularon mediante el método propuesto por Hayashi et al. (2000). Para ambos índices se consideró un total de 1000 eritrocitos. Para calcular el índice de toxicidad se utilizó la siguiente fórmula:

$\mathrm{IM}=[$ núm. de $\mathrm{CP} / 1000] \times 100$

En tanto que la genotoxicidad se calculó de la siguiente manera:

$\% \mathrm{MCN}=$ Núm. de $\mathrm{MCN}$ en

$\mathrm{CP} / 1000$ células totales $\times 100$

Los datos se organizaron en el cuadro I. Para cada día de muestreo se realizó una prueba paramétrica (ANOVA de un factor) con los datos individuales de cada lote experimental. En los resultados globales se empleó la prueba de ANOVA de un factor utilizando como datos individuales el promedio de cada lote experimental por día de muestreo. Además, en ambos casos se aplicó la prueba de comparación múltiple de Dunnett $(\mathrm{p}<0.05)$ cuando la prueba 
ANOVA mostraba diferencias significativas. Todas las pruebas estadísticas se realizaron mediante el programa Minitab 16.

\section{Aberraciones cromosómicas estructurales en cultivo de linfocitos humanos Obtención de sangre y preparación de soluciones}

Las muestras de sangre se obtuvieron de dos donadores del sexo masculino de 22 y 25 años. Los criterios de inclusión fueron: ningún tipo de enfermedad, ningún tratamiento médico y ausencia de tatuajes.

Se prepararon soluciones madre para ambos extractos de pigmentos a una concentración de $10 / 10 \mathrm{~mL}$, las cuales se disolvieron en agua/etanol en proporción 9:1.

\section{Tratamientos y cultivo de linfocitos}

Para determinar las concentraciones que se emplearon en los tratamientos se realizaron ensayos preliminares de citotoxicidad. Se seleccionaron las concentraciones finales que mostraron una toxicidad menor al $20 \%$ sobre el índice mitótico (\% IM).

El procedimiento fue el siguiente: se prepararon nueve tubos Corning de plástico para el cultivo de linfocitos con una repetición cada uno. A cada tubo se le agregaron $5 \mathrm{~mL}$ de medio Biowest (RPMI 1640) con $0.1 \mu \mathrm{L}$ de fitohemaglutinina al $4 \%$ (Microlab) más $0.5 \mathrm{~mL}$ de muestras de sangre heparinizada de dos donadores sanos. Las soluciones fueron incubadas a $37^{\circ} \mathrm{C}$. A las $48 \mathrm{~h}$ de iniciado el cultivo se les adicionaron $100 \mu \mathrm{l}$ de las siguientes concentraciones de pigmentos de tinta negra: primer tubo, $70 \mathrm{mg} / \mathrm{mL}$; segundo tubo, $100 \mathrm{mg} / \mathrm{mL}$; tercer tubo, $130 \mathrm{mg} / \mathrm{mL}$. Respecto de la tinta blanca se utilizo el mismo volumen $(100 \mu \mathrm{L})$ para cada concentración, colocando en el tubo cuatro la dosis de $10 \mathrm{mg} / \mathrm{mL}$; en el tubo cinco se agregó la dosis de $30 \mathrm{mg} / \mathrm{mL}$, y en el tubo seis la dosis de $50 \mathrm{mg} / \mathrm{mL}$. En este tiempo se agregaron al cultivo de linfocitos las concentraciones de tintas, porque es el momento en que se estabiliza el cultivo e inicia el proceso de división celular. Además, se designó al tubo siete como testigo negativo, al cual únicamente se le adicionó fitohemaglutinina. Además se empleo otro testigo negativo correspondiente al tubo ocho en el cual los cultivos fueron sometidos a una solución de $100 \mu \mathrm{L}$ de agua/etanol en proporción 9:1 que correspondió. Ffinalmente, el tubo nueve se designó como testigo positivo, al cual se añadieron $200 \mu \mathrm{L}$ de bleomicina a una concentración de $13 \mu \mathrm{g} / \mathrm{mL}$.

A las $70 \mathrm{~h}$ de iniciado el cultivo se agregaron 0.2 $\mathrm{mL}$ de colchicina al $0.05 \%$ (Sigma). Durante todo este proceso los cultivos se incubaron a $37^{\circ} \mathrm{C}$.

\section{Cosecha}

A las 72 h se llevó a cabo la cosecha de células de linfocitos humanos de la siguiente forma: los tubos de cultivo con los tratamientos y los testigos se centrifugaron a $1500 \mathrm{rpm}$ durante $10 \mathrm{~min}$ a temperatura ambiente. Se eliminó el sobrenadante de cada tubo e inmediatamente el botón se suspendió con solución hipotónica a $37{ }^{\circ} \mathrm{C}$, dejándolo reposar durante 20 min en la incubadora. Transcurrido este tiempo se sacaron los tubos y se les agregó $1 \mathrm{~mL}$ de fijador frío Carnoy 3:1 (prefijación), se agitó por inversión y se centrifugó a $1500 \mathrm{rpm}$ durante $10 \mathrm{~min}$. Después se desechó el sobrenadante y el botón se suspendió nuevamente con $10 \mathrm{~mL}$ de fijador Carnoy y se agitó rápidamente por inversión (para no perder el botón por aglutinación). El paso anterior se repitió hasta completar tres lavados para después elaborar las laminillas, las cuales se hicieron por goteo a 1.0-1.5 m de altura, realizando como mínimo tres y dejándolas secar al aire. Finalmente, con la finalidad de distinguir cada cromosoma y observar en ellos alteraciones ( $p$. ej., inversiones), las laminillas se procesaron para teñir las bandas $\mathrm{G}$ (tren: tripsina/amortiguador libre de $\mathrm{Ca}^{++}$y Mg$^{++}$/amortiguador libre de $\mathrm{Ca}^{++} \mathrm{y} \mathrm{Mg}^{++}$/ Giemsa/agua).

\section{Evaluación de la genotoxicidad e índice mitótico}

Para el análisis de aberraciones cromosómicas, se utilizó la técnica de doble ciego a fin de eliminar la tendencia subjetiva de correlacionar los resultados entre los grupos experimentales y los testigos. Una vez realizadas las tinciones se observaron por cultivo 50 metafases con un rango de 44 a 47 cromosomas contabilizando las aberraciones detectadas.

El índice mitótico (IM) se determinó por medio del análisis de 1000 células estimuladas (inicio de división celular). La referencia que se tomó para determinar qué células entraban en división fue el aumento en el tamaño de sus núcleos y su tinción nítida; en cambio, los núcleos de células no estimuladas eran muy pequeños y presentaron coloración azul muy intensa cuando se observaron al microscopio (Husgafvel-Pursiainen 1987). La fórmula para obtener el porcentaje de IM que se utilizó en el estudio fue $\mathrm{IM}=$ núm. de metafases $/ 1000$ y \% $\mathrm{IM}=\mathrm{IM} \times 100$.

\section{Análisis estadístico}

El mismo procedimiento estadístico se realizó para el ensayo de micronúcleos, que consistió en la prueba de ANOVA de un factor y una prueba de comparación múltiple de Dunnett cuando fue requerida. 


\section{RESULTADOS}

\section{Ensayo de micronúcleos Toxicidad}

Con el fin de evaluar el comportamiento tóxico de ambos pigmentos a dosis de 30, 60 y $90 \mathrm{mg} / \mathrm{kg}$, se llevó a cabo la prueba de ANOVA para cada día (24, 48, 72, 96 y 120 h). Además, se evaluó si el medio agua-etanol en que se disolvieron los pigmentos también provocaba toxicidad (Fig. 1).

A las $24 \mathrm{~h}$ se obtuvo un valor de $F_{\text {obs }}=3.66>=$ 2.313 , es decir, existen diferencias significativas con relación a la proporción de células policromáticas y normocromáticas. Sin embargo, la prueba de comparación múltiple de Dunnett $(\mathrm{p}<0.05)$ indicó que solamente el tratamiento con pigmento blanco de $60 \mathrm{mg} / \mathrm{kg}$ mostró dicha diferencia.

A partir de los resultados de la prueba de ANOVA los valores fueron los siguientes: a las $48 \mathrm{~h}: F_{\text {obs }}=$ $12.69>=2.313$; a las $72 \mathrm{~h}: F_{\text {obs }}=9.42>=2.313$; a las $96 \mathrm{~h}: F_{\mathrm{obs}}=12.58>=2.313$; y a las $120 \mathrm{~h}: F_{\mathrm{obs}}=$ $7.50>=2.313$. Así pues, los valores promedio del $\%$ IM mostraron diferencias significativas y mediante la prueba de Dunnett $(\mathrm{p}<0.05)$ se observó que las tinta blanca y negra en sus tres dosis indujeron toxicidad con excepción del tratamiento de agua-etanol.

Por último, se realizó un análisis estadístico que contempló los cinco días de muestreo para observar el resultado global (Fig. 2). Los valores promedio del efecto toxicológico (Cuadro I) evaluados de manera global mostraron un valor calculado de $F_{\text {obs }}=6.46$ $>=2.313$, es decir, los valores promedio de los tratamientos presentaron diferencias significativas con relación a la proporción de células policromáticas y normocromáticas. La prueba de comparación múltiple de Dunnett $(\mathrm{p}<0.05)$ indicó que los tratamientos expuestos a pigmentos fueron los que mostraron diferencias significativas.

\section{Genotoxicidad}

Los valores promedio para cada día de muestreo fueron los siguientes:

A las 24 h (Fig. 3) se obtuvo un valor de $F_{\text {obs }}$ $=18.13>=2.313$, es decir, con diferencias significativas en la presencia de células policromáticas micronucleadas respecto del control negativo. La prueba de comparación múltiple de Dunnett $(\mathrm{p}<$ 0.05 ) indicó que sólo los tratamientos de pigmento negro de 60 y $90 \mathrm{mg} / \mathrm{kg}$ presentaron dicha diferencia significativa.

A las $48,72,96$ y $120 \mathrm{~h}\left(F_{\text {obs }}=22.24>=2.313\right.$; $F_{\text {obs }}=19.88>=2.313 ; F_{\text {obs }}=16.62>=2.313$, y $F_{\text {obs }}$ $=35.98>=2.313$, respectivamente), los valores de la prueba de ANOVA indicaron la existencia de diferencias estadísticamente significativas. Mediante la prueba de Dunnett $(\mathrm{p}<0.05)$ se puntualizó que todos los tratamientos con los pigmentos, a excepción del grupo tratado solamente con agua-etanol, generaron un aumento significativo de micronúcleos respecto al control negativo.

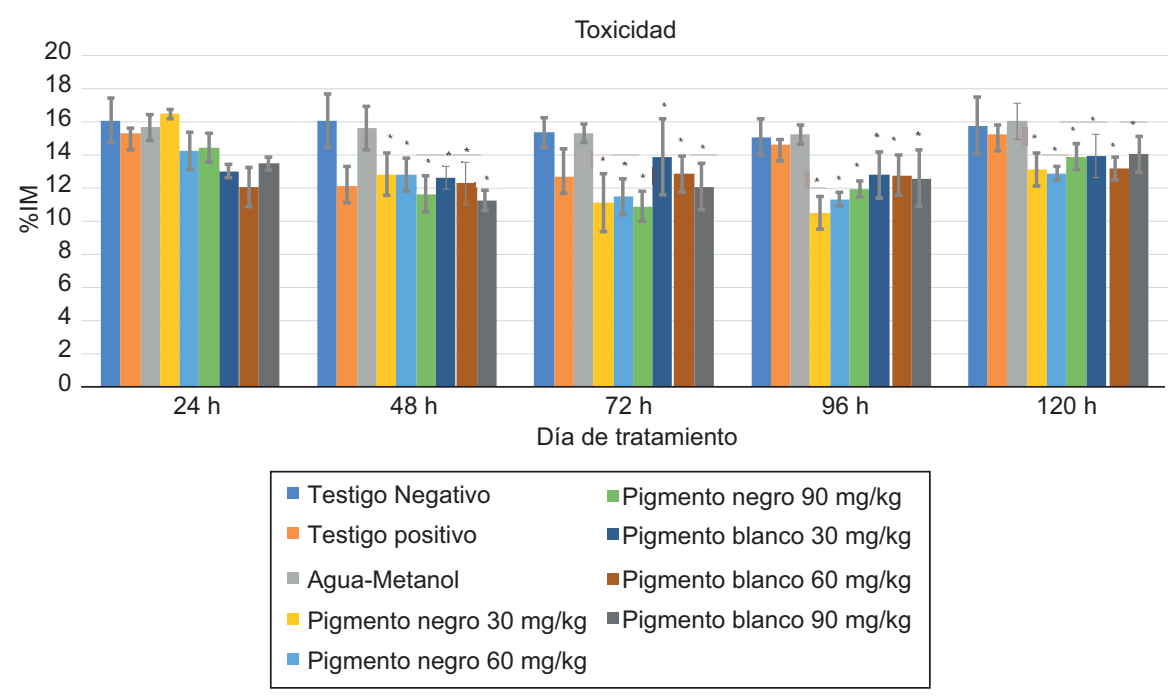

Fig. 1. Se observan los valores de toxicidad para cada tratamiento durante los cinco días de muestreo. A las $24 \mathrm{~h}$ únicamente el pigmento blanco a $60 \mathrm{mg} / \mathrm{kg}$ indujo daño. De las $48 \mathrm{~h}$ en adelante todos los tratamientos con pigmentos indujeron toxicidadDe las $48 \mathrm{~h}$ en adelante todos los tratamientos con pigmentos indujeron toxicidad, siendo este efecto estadisticamente significativo. ${ }^{*}$ Tratamientos con diferencias estadísticamente significativas mediante comparación múltiple de Dunnett $(\mathrm{p}<0.05)$. 


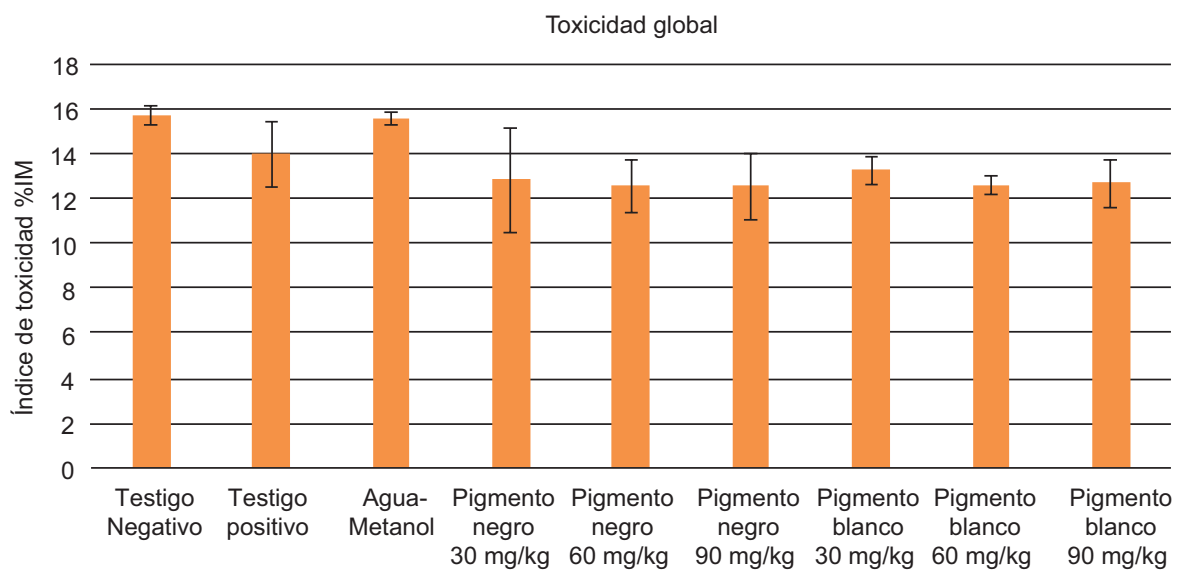

Tratamientos

Fig. 2. Porcentaje de toxicidad global de cada día de muestreo para todos los tratamientos. Se observa que todos los tratamientos con pigmentos indujeron toxicidad respecto al testigo * Tratamientos con diferencias estadísticamente significativas respecto a la media del testigo negativo mediante comparación múltiple de Dunnett $(\mathrm{p}<0.05)$.

Como último análisis de la genotoxicidad se calculó el ANOVA de un factor contemplando los primeros cinco días de muestreo para observar un resultado global (Fig. 4). De este modo los valores promedio del efecto genotóxico (Cuadro I) evaluados de manera global mostraron un valor calculado de $F_{\text {obs }}=11.19>=2.313$, confirmando diferencias estadísticas en la inducción de micronúcleos en eritrocitos de sangre periférica de ratón. Por ello se aplicó la prueba de comparación múltiple de Dunnett $(\mathrm{p}<0.05)$, la cual permite, mediante la comparación de los promedios de tratamientos con el promedio del testigo negativo, determinar qué tratamiento presenta una diferencia significativa. El resultado fue que todos los tratamientos de las tintas produjeron dichas diferencias estadísticamente significativas.

\section{Cultivo de linfocitos humanos Índice mitótico}

Se obtuvo el índice mitótico para cada uno de los tratamientos, contemplado las muestras de ambos donadores (Cuadro I).

Los resultados del ANOVA $\left(F_{\mathrm{ob} S}=94.14>=3.50\right)$ mostraron que existen diferencias significativas entre los tratamientos. La prueba de comparación múltiple de Dunnett $(\mathrm{p}<0.05)$ indicó que los tratamientos que presentaron diferencias respecto al testigo negativo fueron los tres tratamientos de los extractos de pigmentos de tinta negra y los tratamientos con pigmentos de tinta blanca con concentraciones de 30 y $50 \mathrm{mg} / \mathrm{mL}$. Por lo anterior, se puede concluir que estos tratamientos son citotóxicos (Fig. 5).

\section{Aberraciones cromosómicas}

Los resultados del ANOVA $\left(F_{\text {obs }}=8.33>=3.50\right)$ mostraron diferencias significativas entre tratamientos (Cuadro I; Fig. 6). Mediante la comparación múltiple de Dunnett $(\mathrm{p}<0.05)$ se determinó que el único tratamiento que mostró una diferencia estadísticamente significativa en la inducción de aberraciones cromosómicas estructurales fue el de pigmentos de tinta blanca de $10 \mathrm{mg} / \mathrm{mL}$ (Fig. 7).

\section{DISCUSIÓN Y CONCLUSIONES}

El ANOVA aplicado a los valores promedio de la proporción de células policromáticas y normocromáticas (toxicidad) dejó clara evidencia de que ambos pigmentos causan efecto citogenotóxico sobre las células sanguíneas del ratón CD-1, lo cual estaría asociado principalmente con los componentes químicos integrados en la elaboración de los pigmentos.

Peta et al. (2015) determinaron la presencia de seis hidrocarburos aromáticos policíclicos (HAP): fenantreno, naftalen, fluoranteno, pireno y benzo(g,h,i) perileno, señalando que el fluoranteno presenta concentraciones mayores a las permitidas por el Consejo Europeo en cuanto a tintas de color negro. Por lo tanto, concentraciones altas de este HAP estarían relacionadas con su nivel de toxicidad, el estrés oxidativo y quizá la genotoxicidad provocada por la aplicación de la tinta negra en cultivo de bacterias y otros organismos. Los resultados del presente estudio son respaldados por las afirmaciones de estos 


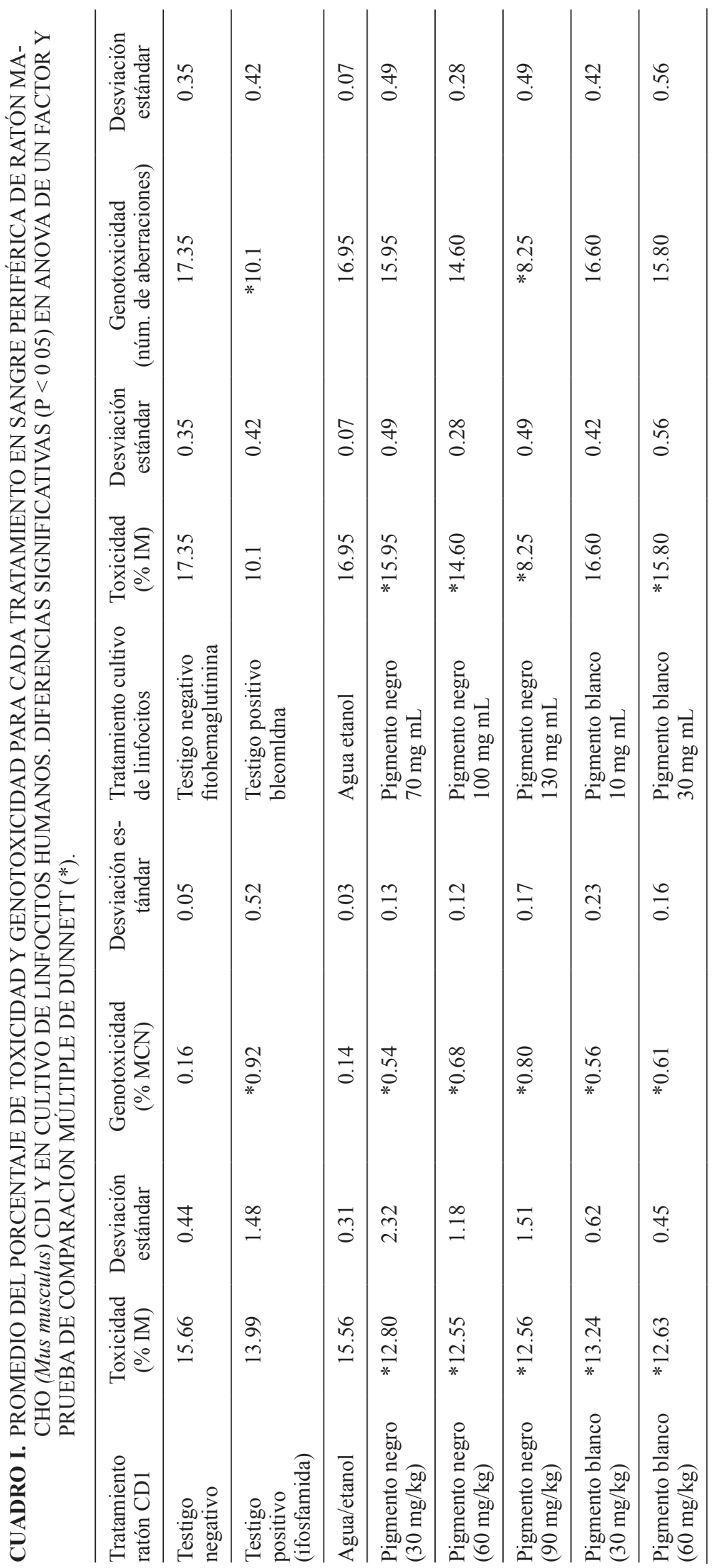




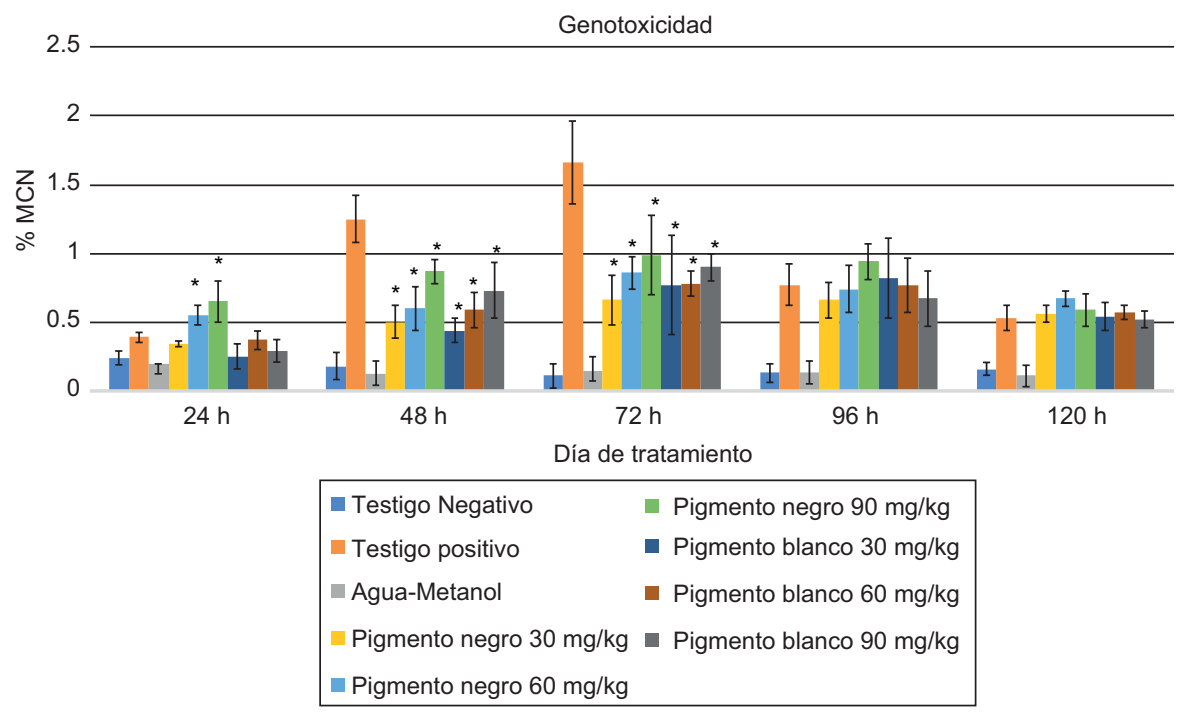

Fig. 3. Se observa el valor del índice de genotoxicidad para cada tratamiento durante los cinco días de muestreo. A las $24 \mathrm{~h}$ sólo el pigmento negro a dosis de 60 y $90 \mathrm{mg} / \mathrm{kg}$ indujo aumento en la producción de micronúcleos, pero de las $48 \mathrm{~h}$ en adelante todos los grupos mostraron diferencias significativas respecto al control negativo. *Tratamientos con diferencias estadísticamente significativas mediante comparación con el testigo negativo de acuerdo con la prueba múltiple de Dunnett $(\mathrm{p}<0.05)$.

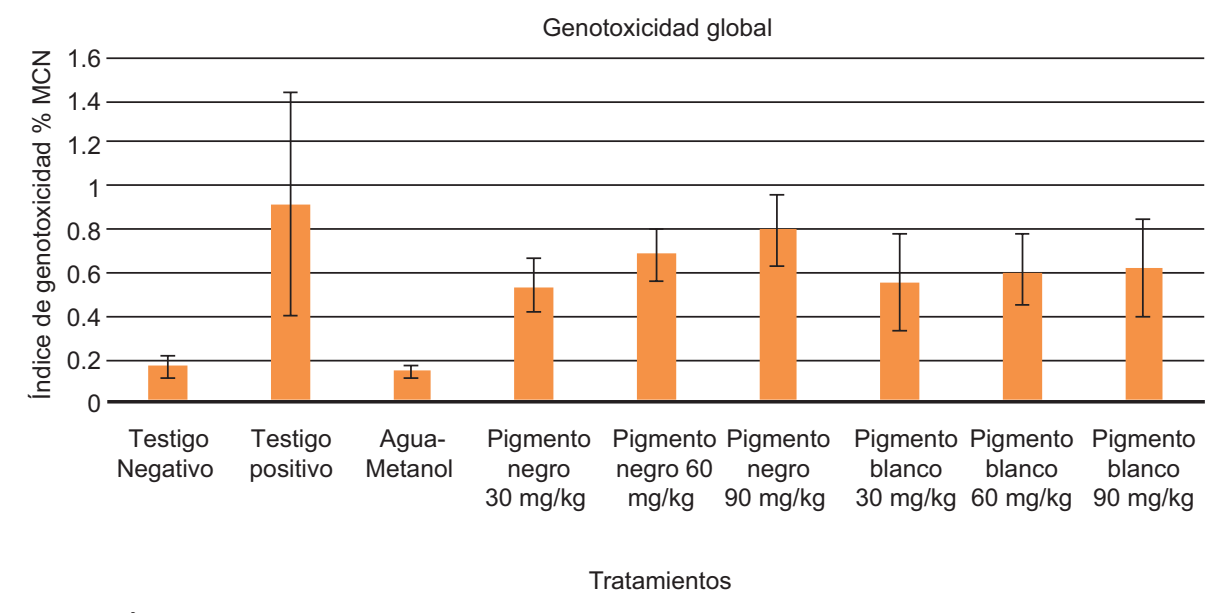

Fig. 4. Índice de genotoxicidad global obtenido para cada tratamiento. Se observa que todos los tratamientos expuestos a pigmentos negros y blancos produjeron un aumento en la inducción de micronúcleos. *Tratamientos con diferencias estadísticamente significativas en comparación con los datos promedio del testigo negativo de acuerdo con la prueba múltiple de Dunnett $(\mathrm{p}<0.05)$. 


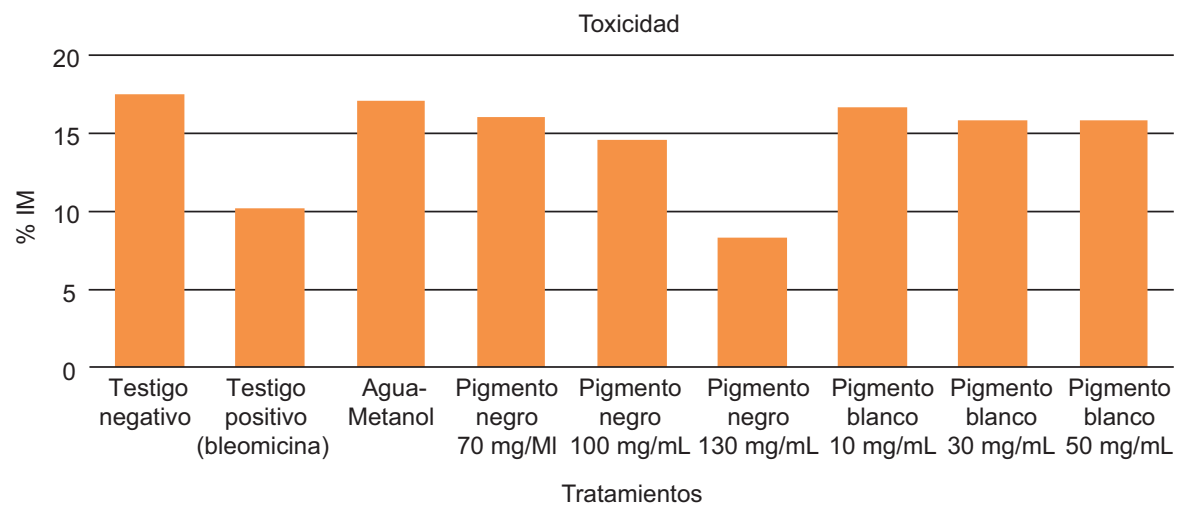

Fig. 5. Valores del índice mitótico para cada tratamiento en los cultivos de linfocitos. Se observa que todos los tratamientos expuestos al pigmento negro y los expuestos a $30 \mathrm{y}$ $50 \mathrm{mg} / \mathrm{ml}$ del pigmento blanco produjeron disminución en la división celular respecto al testigo negativo. ${ }^{*}$ Tratamientos con diferencias estadísticamente significativas mediante comparación con datos promedio del testigo negativo de acuerdo con la prueba múltiple de Dunnett $(\mathrm{p}<0.05)$.

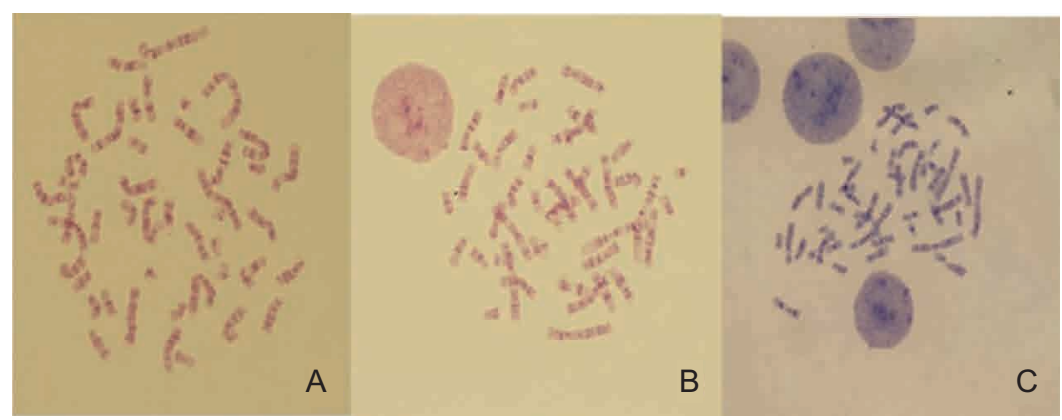

Fig. 6. Metafases observadas con aumento de $100 \times$. No se observan alteraciones. (a) Control negativo, (b) pigmento negro $(90 \mathrm{mg} / \mathrm{kg}$ ) y (c) pigmento blanco (60 mg/kg).

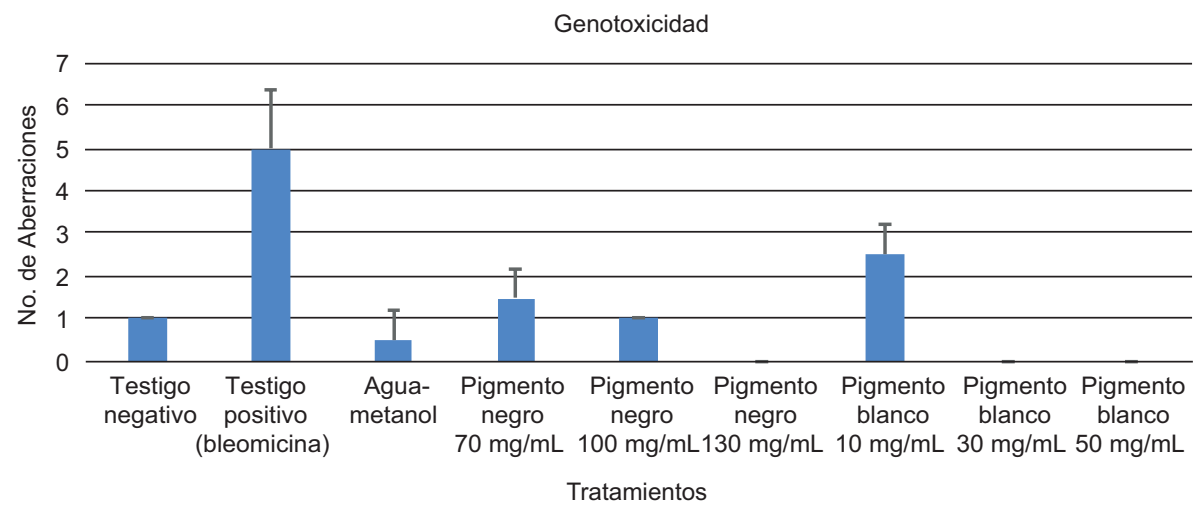

Fig. 7. Promedio de aberraciones cromosómicas para cada tratamiento. Se observa que únicamente el tratamiento con pigmento blanco a una concentración de $10 \mathrm{mg} / \mathrm{mL}$ produjo aberraciones cromosómicas estructurales con diferencia estadísticamente significativa respecto al testigo negativo. *Tratamientos con diferencias estadísticamente significativas mediante comparación con los valores promedio del testigo negativo de acuerdo con la prueba múltiple de Dunnett $(\mathrm{p}<005)$. 
investigadores en lo referente a que la tinta negra utilizada en el experimento provocó disminución en el porcentaje de la división celular (toxicidad) y daño clastogénico en células sanguíneas periféricas del ratón $\mathrm{CD}-1$, efectos debidos a la alta concentración de HAP y quizá a la presencia de impurezas inorgánicas y orgánicas en la composición química de la tinta negra.

De acuerdo con la literatura, el efecto genotóxico de cualquier agente químico comúnmente suele observarse $48 \mathrm{~h}$ después de su administración, lo cual se comprobó en este estudio (Hayashi et al. 2000, Flores et al. 2013). Sin embargo, el efecto mayor se detectó a las 72 y 96 h postratamiento. Esto podría deberse, por un lado, a que la vía de administración fue subcutánea, y por otro a que los HAP mencionados actúan como promutágenos, es decir, deben pasar por un proceso de metabolización. Cabe considerar que específicamente el fluoranteno ha demostrado in vitro que aumenta la expresión de CYP 450, enzimas necesarias para la biotransformación de los promutágenos (Huang et al. 2012). Por lo tanto, este hidrocarburo contenido en la tinta negra podría estar implicado en su capacidad genotóxica sobre las células sanguíneas del ratón CD1.

La tinta blanca está elaborada primordialmente con dióxido de titanio (incluso en forma de nanopartículas) u óxido de zinc, plomo y cadmio (Eghbali et al. 2014). Estudios previos sobre la genotoxicidad de nanopartículas de dióxido de titanio no han demostrado que éste sea inductor de micronúcleos; sin embargo, otros estudios in vitro (ensayo de micronúcleos e intercambio de cromátidas hermanas) sí han demostrado puede inducir genotoxicidad (Chen et al. 2014). Los resultados del presente trabajo podrían estar asociados a la presencia de dióxido de titanio, plomo y cadmio contenidos en la tinta blanca, los cuales podrían ser los causantes del efecto citogenotóxico sobre los eritrocitos de la sangre periférica de ratón CD1.

En el caso de los cultivos de linfocitos humanos expuestos a concentraciones de tinta negra y tinta blanca, los tratamientos tuvieron un efecto citotóxico al disminuir las células en división; sin embargo, ninguno incrementó de manera significativa la generación de aberraciones cromosómicas.

En el casó especifico de la tinta negra, su composición se basa en compuestos derivados de carbón y HAP, los cuales, como señalan Hogsberg et al. (2013) tienen la capacidad de provocar un aumento en la generación de especies reactivas de oxígeno, lo cual desembocaría en un aumento en la producción de estrés oxidativo: Esto, a su vez, podría verse reflejado en la generación de mutaciones puntuales y aberraciones cromosómicas. Se sabe que la mayoría de los HAP actúan como promutágenos, es decir, deben pasar por un proceso metabólico para tener la capacidad de inducir daño genético. En este caso los cultivos de linfocitos carecen de una fuente externa para la metabolización, por lo que no tienen la capacidad de activar los HAP, y éstos en consecuencia no pueden inducir daño genético detectable en los cultivos celulares. Por ello, a pesar de que la tinta negra contiene compuestos indeterminados, se deduce que el daño que podrían ocasionar se relaciona con los HAP. Como ejemplo, en el ensayo llevado a cabo en ratones machos, los cuales poseen una fuente de metabolización (el hígado), fue posible detectare micronúcleos. Por otro lado, las tres concentraciones de tinta negra produjeron una baja en el índice mitótico, lo cual es clara muestra de efecto citotóxico. Como señalan Peta et al. (2015), los HAP presentes en la tinta negra solo pudieron explicar un porcentaje muy bajo del estrés oxidativo generado, por lo cual dicha toxicidad podría derivarse de algunos de los compuestos no identificados que forman parte de la composición química de la tinta.

La tinta blanca, como ya se estableció, está conformada principalmente por dióxido de titanio $\mathrm{u}$ óxido de zinc y en algunos casos por plomo y cadmio. Chen et al. (2014) señalaron que las nanopartículas de dióxido de titanio tienen la capacidad de provocar daño genético mediante la generación de estrés oxidativo, aunque en este estudio no se detectaron aberraciones cromosómicas en el cultivo de linfocitos, lo cual indica que podría estar relacionado con el tamaño, forma y concentración de las nanopartículas. También se infiere que dentro de la tinta blanca hay compuestos no detectados que podrían desempeñar un papel en la inducción de daño genético, pero que antes tendrían que pasar por un proceso de activación metabólica. Además, Jugan et al. (2012) reportan que la capacidad de las nanopartículas de dióxido de titanio para provocar daño ocurre por la vía fotocatalítica, de ahí que la exposición a la luz sea necesaria para la producción de especies reactivas de oxígeno.

\section{AGRADECIMIENTOS}

Al posgrado en Ciencias Biológicas de la Universidad Nacional Autónoma de México y al programa de becas del Consejo Nacional de Ciencia y Tecnología (CONACyT) por su apoyo económico a través de la beca CVU:778963. 


\section{REFERENCIAS}

Albertini R.J., Anderson D., Douglas G.R., Hagmar L., Hemminki K., Merlo F., Natarajan A.T., Norppa H., Shuker D.E., Tice R., Waters M.D. y Aitio A. (2000). IPCS guidelines for the monitoring of genotoxic effects of carcinogens in humans. International programme on chemical safety. Mutat. Res. 463 (2), 111-172. https:// doi.org/10.1016/S1383-5742(00)00049-1

Bäumler W., Vasold R., Lundsgaard J. y Talberg H. (2003). Chemicals used in tattooing and permanent make up products. En: Workshop on the technical/scientific and regulatory issues on the safety of tattoos, body piercing and related practices (Papameletiou D., Schwela D., Zenie A. y Bäumler W., Eds.). Ispra, European Commission, 21-48.

Beute T.C., Miller C.H., Timko A.L. y Ross E.V. (2008). In vitro spectral analysis of tattoo pigments. Dermatol Surg. 34 (4), 508-515. https://doi.org/10.1111/j.15244725.2007.34096.x

Calderón-Segura M.E., Gómez-Arroyo S., VillalobosPietrini R. y Espinosa-Ramírez M. (1999). In vivo and in vitro promutagen activation by Vicia faba of thiocarbamate herbicides molinate and butylate to products inducing sister chromatid exchanges in human lymphocyte cultures. Mutat. Res. 438 (2), 81-88. https://doi.org/10.1016/s1383-5718(98)00152-1

Chen T., Yan J. y Yan L. (2014). Genotoxicity of titanium dioxide nanoparticles. J. Food Drug Anal. 22, 95-104. https://doi.org/10.1016/j.jfda.2014.01.008

CONAPRED (2015). El uso de tatuajes no debe ser motivo de discriminación. Boletín de prensa. Consejo Nacional Para Prevenir la Discriminación, México [en línea]. http://www.conapred. org. $\mathrm{mx} /$ index.php? contenido=boletin\&id=759\&id opcion=\&op=213 12/06/2017

Eghbali K., Mousavi Z. y Ziarati P. (2014). Determination of heavy metals in tattoo ink. Biosci. Biotech. Res. Asia 11 (2), 941-946.

FDA (2007). Guidance for Industry and Other Stakeholders: Redbook 2000 Toxicological Principles for the Safety Assessment of Food Ingredients. U.S. Food and Drug Administration [en línea]. https://www. fda.gov/regulatory-information/search-fda-guidancedocuments/guidance-industry-and-other-stakeholderstoxicological-principles-safety-assessment-foodingredients-0 11/05/ 2017

Flores S., Barrera H., Frausto A., Chávez D., Hernández A., Herrera V. y Nájera L. (2013). Efectos citogenéticos de la fórmula comercial de una tableta antigripal en los eritrocitos de sangre periférica de ratón árabe (Mus musculus Linnaeus, 1758). Biocyt. 6 (20), 388-397.
Forte G., Petrucci F., Cristaudo A. y Bocca B. (2009a). Market survey on toxic metals contained in tattoo inks. Sci. Total Environ. 407 (23), 5997-6002. https://doi. org/10.1016/j.scitotenv.2009.08.034

Forte G., Petrucci F., Cristaudo A. y Bocca B. (2009b). Quantification of sensitizing metals in tattooing pigments by SF-ICP-MS technique. Open Chem. Biomed. Meth. J. 2, 42-47. https://doi. org $/ 10.2174 / 1875038900902020042$

Gómez-Arroyo S., Calderón-Segura M.E. y VillalobosPietrini R. (1995). Sister chromatid exchange in human lymphocytes induced by propoxur following plant activation by Vicia faba. Environ. Mol. Mutagen. 26 (4), 324-330. https://doi.org/10.1002/ em. 2850260408

Hayashi M., MacGregor J.T., Gatehous D.G., Adler I.D., Blakey D.H., Dertinger S.D., Krishna G., Morita T., Russo A. y Sutou S. (2000). In vivo rodent erythrocyte micronucleus assay. II. Some aspects of protocol design including repeated treatments, integration with toxicity testing, and automated scoring. Environ. Mol. Mutagen. 35 (3), 234-252. https://doi.org/10.1002/ (SICI) 1098-2280

Hayashi M., Hamada S., Morita T., Wakata A., Asanami S., Hosoya S., Ozawa S., Kondo K., Nakajima M., Shimada H., Osawa K., Kondo Y., Asano N., Sato S., Tamura H., Yamija N., Marshall R., Moore C., Blakey D. H., Schechtman L.M., Weaver J.L., Torous D.K., Proudlock R., Ito S. y Namiki C. (2001). Evaluation of the rodent micronucleus assay by a 28-day tratment protocol: Summary of the 13th collaborative study by The Collaborative Study Group for the Micronucleus Test (CSGMT)/Environmental Mutagen Society of Japan (JEMS)-Mammalian Mutagenicity Study Group (MMS). Environ. Mol. Mutagen. 37 (2), 93-110. https://doi.org/10.1002/em.1017

Heywood W., Patrick K., Smith A.M., Simpson J.M., Pitts M.K., Richters J. y Shelley J.M. (2012). Who gets tattos? Demographic and behavioral correlates of ever being tattoed in a representative sample of men and women. Ann. Epidemiol. 22 (1), 51-56. https://doi. org/10.1016/j.annepidem.2011.10.005

Hogsberg T., Jacobsen N., Clausen P. y Serup J. (2013). Black tattoo inks induce reactive oxygen species production correlating with aggregation of pigment nanoparticles and product brand but not with the polycyclic aromatic hydrocarbon content. Exp. Dermatol. 22 (7), 464-469. https://doi.org/10.1111/exd.12178

Huang M.C., Chen F.Y., Chou M.T. y Su J.G.J. (2012). Fluoranthene enhances p53 expression and decreases mutagenesis induced by benzo[a]pyrene. Toxicol. Lett. 208, 214-224. https://doi.org/10.1016/j.toxlet.2011.11.011 
Husgafvek-Pursiainen K. (1987). Sister-chromatid exchange and cell proliferation in cultured lymphocytes of passively and actively smoking restaurant personnel. Mut. Res. 190, 211-215. https://doi.org/10.1016/01657992(87)90031-5

Jacobsen E., Tonning K., Pedersen E., Serup S., Hogsberg T. y Nielsen E. (2012). Chemical substances in tattoo ink. Survey of Chemical Substances in Consumer Products 116 [en línea]. https://www2.mst.dk/Udgiv/publications/2012/03/978-87-92779-87-8.pdf 4/05/2018

Jugan M., Barillet S., Simon-Deckers A., Herlin N., Sauvagio S., Douki T. y Carriere M. (2012). Titanium dioxide nanoparticles exhibit genotoxicity and impair DNA repair activity in A549 cells. Nanotoxicology 6 (5), 501-513. https://doi.org/10.3109/17435390.20 11.587903

Megías M., Molist P. y Pombal M.A. (2018). Atlas de histología vegetal y animal. Técnicas histológica protocolos. Departamento de Biología Funcional y Ciencias de la Salud, Facultad de Biología, Universidad de Vigo,
España, 53 pp. [en línea]. https://mmegias.webs.uvigo. es/descargas/tecnicas-protocolos.pdf 6/02/2018

Laux P., Tralau T., Tentschert J., Blume A., Al Dahouk S., Bäumler W., Bernstein E., Bocca B., Alimont A., Colebrook H., de Cuyper C., Dähne L., Hauri U., Howars P., Janssen P., Katz L., Klitsman B., Kluger N., Krutak L., Platzek T., Scott-Lang V., Serup J., Teubner W., Schreiver I., Willknif E. y Luch A. (2016). A medical-toxicological view of tattooing. Lancet 387 (10016), 395-402. https://doi.org/10.1016/S01406736(15)60215-X

Peta N., Stalter D., Tang J. y Escher B. (2015). Bioanalytical evidence that chemicals in tattoo ink can induce adaptative stress responses. J. Hazard. Mater. 296, 192200. https://doi.org/10.1016/j.jhazmat.2015.04.051

Wenzel S.M., Rittmann I., Landthaler M. y Baumler W. (2013). Adverse reactions after tattooing: review of the literature and comparison to results of a survey. Dermatology 226 (2), 138-47. https://doi. org/10.1159/000346943. 